\section{Hodgkin lymphomas in HIV/AIDS patients when treated with combined antiretroviral therapy: further studies are needed for understanding the pathogenesis of developing hodgkin lymphomas in HIV}

\section{Pranab Kumar Bhattacharya ${ }^{[1]}$}

[1]. Department of Pathology, School of Tropical Medicine, Kolkata, West Bengal, India.

\section{Dear Editor,}

I read an interesting article published in your journal titled: Malignancies in HIV/AIDS patients attending an outpatient clinic at Santa Casa de Misericodia de Vitória, State of Espirito Santo, Brazil by Lauro Ferreria da Silva Pinto et al. published in Revista da Sociedade Brasileira de Medicina Tropical/Journal of the Brazilian Society of Tropical Medicine, Volume 45, NovemberDecember, pp. 687-690, 2012. I wish to share my views on this article, especially on the Hodgkin lymphomas (HL) in HIV patients treated with combined antiretroviral therapy (cART).

Antiretroviral therapy (ART) for HIV-infected patients has definitely improved the survival of patients. However, the longterm use of ART has some adverse effects. The widespread use of cART since the mid 1990s has led to a significant decrease in Kaposi sarcoma and lymphomas ${ }^{1}$.

In the current cART era, an increased mortality rate caused by several non-AIDS defining malignancies (NADM), such as cervical cancer, lung cancers, laryngeal cancer, colonic adenocarcinomas have been observed. This author has also diagnosed these NADMs in the cART-treated HIV-infected population in the provinces of the State of West Bengal, India, while serving as a Professor in Pathology in Tertiary Care at the Post Graduate Teaching Hospital of Kolkata, West Bengal, Institute of Post Graduate Medical Education \& Research, Kolkata (IPGMER) during 2002-2010. One case of renal cell carcinoma (RCC) was also detected. Bidi (raw tobacco) smoking ( $>30$ per day) is very common among the HIV-infected population (having $<200 \mathrm{CD} 4$ count) who are from a very low socioeconomic stratum putting them at high risk of lung and laryngeal cancers (Squamous-cell carcinoma - SCC). Here, the

Address to: Prof. Pranab Kumar Bhattacharya. Dept. of Pathology, School of Tropical Medicine, Kolkata. 108, Chittaranjan Avenue, Kolkata-73, West Bengal, India.

Phone: 9192 3151-0435

e-mail: profpkb@yahoo.co.in

Received 11 February 2013

Accepted 10 April 2013 majority of HIV patients were treated with nucleoside reverse transcriptase inhibitors (NRTIs) while some were treated with non-nucleoside reverse transcriptase inhibitors (NNRTIs).

As a histopathologist, Ihave reported non-Hodgkin lymphomas (NHL), of which 7 cases were immunohistochemically proved to be of diffuse large B-cell (DLBCL type) and one case of mycosis fungoides (T-cell type). However, surprisingly no primary brain NHL was detected in my long career of 25 years since 1987 as a histopathologist in Kolkata.

Interestingly, though Lauro Ferreira da Silva Pinto's study of 730 patients found only 4 cases of NHL and 2 cases of HL (histological type not mentioned) in a study (an MD thesis under my guidance in pathology), of 52 cancer cases detected in HIV/AIDS patients undergoing cART therapy, we found nine $(18 \%)$ cases of HL. In these cases that were presented with fever, lymphadenopathy, hepatomegaly, and other systemic manifestations, the cervical lymph node biopsies showed that seven cases were of a mixed-cellular type and two cases were of the lymphocytic depletion type within a median duration of treatment of 3-4 months.

Incidences of HL seem and probably significantly rising unnaturally in the HIV-infected population of the West Bengal Provinces in India more than the conventional B-cell NHL cases, which we have known so far from CDC. Is this owing to the fact that cART was started in Kolkata in 1996? Alternatively, is it because of immune suppression or the Epstein bar virus (EBV) infection in the cART patients? No studies on this aspect can be found in the literature from India. Studies in the United States (US) and in the United Kingdom have probably also reported the increase in the incidence of HL when compared with the precART era. For example, among the people with AIDS in the US, incidences of HL were shown to be elevated 8-fold compared with the general population during the pre-cART era, and this increased significantly to 13 -fold during the cART $\mathrm{era}^{2}$. Excess risk of HL in the US population and among the HIV-infected population in France was also shown to be very high during the pre-cART era. In a French study, HL incidence increased even more (by 1.4-fold) during the cART era when compared with the pre-cART era ${ }^{3}$. In a Swiss HIV cohort study ${ }^{4}$, HL risk was shown to be 3 -fold higher in the cART era when compared with the pre-cART era in an analysis of the first 18 cases, but this was not, however, statistically significant and no increment in the cART era was found in an updated analysis of $47 \mathrm{HL}$ cases.

Is increased HL in the cART era postulated to be related to the actual use of cART with a possible and potential role for certain immunologic mechanisms? Some support for an effect of cART on HL risk was provided by the British ${ }^{5}$ and initial Swiss studies, but these finding were marginally significant and were adjusted little or not at all by considering immune deficiency.

The British study ${ }^{5}$ on the other hand suggested that excess risk of HL might specifically be related to the use of NNRTIs. Immune perturbation and its control by cART are likely to be integral to the development of HIV-associated HL. The relative risk of $\mathrm{HIV}$-associated $\mathrm{HL}$ is 3.5 -fold higher after AIDS 
onset, and a lower CD4 lymphocyte count generally predicts a higher incidence of HL. However, with the most severe immune deficiency $\left(<50 \mathrm{CD} 4\right.$ cells $\left./ \mathrm{mm}^{3}\right)$, HL risk appears to be paradoxically lower. Why? The risk of HL increased significantly by 2.6 -fold during the first three months of cART as per the author's experience and data! This increase may largely be explained by the concurrent CD4 cell count, because this association with duration on cART was greatly attenuated when we included the CD4 count in the same model. Our results also highlight the importance of immuno suppression in the development of HL because when compared with HIV-infected people with a CD4 count of at least 500 cells $/ \mathrm{mm}^{3}$ the HL risk was increased by nearly 10 -fold in those with a CD4 cell count of $50-99$ cells $/ \mathrm{mm}$. Instead, the author suggests here that the increase in HL incidence during the first 3-6 months on cART implies that the clinicians in West Bengal and in the Indian tropics should be highly alert to the possibility of developing HL during cART-induced immune reconstitution. Corroboration and basic understanding of changes in CD4 counts, possibility of EBV in developing HL, and releases of chemokines during immune reconstitution (which we pathologists term as immune reconstitution inflammatory syndrome - IRIS) might provide an insight into the pathogenesis of developing HL amongst HIV patients treated with cART. Further research by histopathologists and hematologists on HIV-associated HL is thus needed in India to establish the cause for HL occurrence and its mechanism.

\section{ACKNOWLEDGMENTS}

Upasana Bhattacharya, Rupak Bhattacharya, Ritwik Bhattacharya, Soumyak Bhattacharya, Rupsa Bhattacharya, Dalia Mukherjee, Oindrila Mukherjee, Debasis Mukherjee, Soma Das, Anuradha De, Surajit Sarkar and Sumana Mukherjee.

\section{CONFLICT OF INTEREST}

The authors declare that there is no conflict of interest.

\section{REFERENCES}

1. Pinto Neto LFS, Milanez MC, Golub JE, Miranda AEB, et al. Malignancies in HIV/AIDS patients attending an outpatient clinic in Vitoria, State of Espírito Santo, Brazil. Rev Soc Bras Med Trop 2012; 45:687-690.

2. Goedert JJ, Cote TR, Virgo P, Scoppa SM, Kingma DW, Gail MH, et al. Spectrum of AIDS-associated malignant disorders. Lancet 1998; 351:1833-1839.

3. Herida M, Mary-Krause M, Kaphan R, Cadranel J, Poizot-Marin I, Rabaud C, et al. Incidence of non-AIDS-defining cancers before and during the highly active antiretroviral therapy era in a cohort of human immunodeficiency virus- infected patients. J Clin Oncol 2003; 21: 3447-3453.

4. Clifford GM, Polesel J, Rickenbach M, Dal Maso L, Keiser O, Koller A, et al. Cancer risk in the Swiss HIV Cohort Study: associations with immunodeficiency, smoking, and highly active antiretroviral therapy. J Natl Cancer Inst 2005; 97:425-432.

5. Powles T, Robinson D, Stebbing J, Shamash J, Nelson M, Gazzard B, et al. Highlyactive antiretroviral therapy and the incidence ofnon-AIDS- defining cancers in people with HIV infection. J Clin Oncol 2009; 27:884-890.

\section{Author's reply: Hodgkin lymphomas in HIV: many questions and few answers}

\author{
Lauro Ferreira da Silva Pinto Neto ${ }^{[1]}$, \\ Maria da Conceição Milanez ${ }^{[2]}$, Jonathan Eric Golub ${ }^{[3]}$ \\ and Angelica Espinosa Barbosa Miranda ${ }^{[4]}$
}

[1]. Departamento de Clínica Médica, Escola Superior de Ciências, Santa Casa de Misericórdia de Vitória, Vitória, ES. [2]. Departamento de Patologia, Escola Superior de Ciências da Saúde, Santa Casa de Misericórdia de Vitória, Vitória, ES. [3]. Division of Infectious Diseases and Bloomberg School of Public Health. Johns Hopkins University, Baltimore, MD, USA. [4]. Departamento de Medicina Social, Universidade Federal do Espírito Santo, Vitória, ES.

\section{Dear Editor,}

We would like to thank Dr. P.K. Bhattacharyya for the letter. The main focus of our paper was to discriminate which malignancies occur in the HIV-positive population at an outpatient clinic in Vitória, State of Espírito Santo, Brazil, as at present, we do not have clear information about the incidence of different types of cancer in these patients in Brazil. The results have shown that the growing incidence of non-AIDS defining cancer in HIVpositive people in Vitória, Brazil, is similar to that of the incidence of AIDS-defining cancer. This is in concordance with what was found in a representative study conducted in the USA ${ }^{1}$. The results point to the need for careful screening of cancer and fighting smoking habits in the HIV-positive population, emphasizing on the special care for those with low CD4 cell counts.

We have reported two cases of Hodgkin lymphomas (HL), both of mixed-cellularity subtype, as described in the discussion. The population studied by us was not big enough for any further analysis concerning factors particularly associated with the incidence of HL found by us. Indeed, different surveys have shown that $\mathrm{HL}$ incidence has significantly risen after the antiretroviral therapy (ART) era and has a unique association with immune status: patients with mild immune suppression are at a bigger risk of HL than those with severe immune suppression or with normal $\mathrm{CD} 4+$ counts $^{2}$. We agree with the assessment that there are several doubts about the pathogenesis of HL in HIV-positive patients. Co-infections and factors linked to geographic location may also have some direct or indirect influence on the different incidence rates for the same type of tumor. Further studies are needed.

\section{REFERENCES}

1. Shiels MS, Pfeiffer RM, Gail MH, Hall HI, Li J, Chaturvedi AK, et al. Cancer burden in HIV-infected population in the United States. J Natl Cancer Inst 2011; 103:753-762.

2. Carbone A, Gloghini A, Serraino D, Spina M. HIV-associated Hodgkin lymphoma. Curr Opin HIV AIDS 2009; 1:3-10.

Address to: Dr. Lauro Ferreira da Silva Pinto Neto. Depto Clínica Médica/ EMESCAM. Rua Dr. João Santos Neves 143, 29019-180 Vitória, ES.

Fax: 5527 3212-7200.

e-mail: lauro.neto@emescam.br

Received 08 March 2013

Accepted 10 April 2013 